\title{
ESTRUTURA DA COMUNIDADE ARBÓREA DE FRAGMENTOS DE FLORESTA ATLÂNTICA OMBRÓFILA SUBMONTANA NA REGIÃO DE IMBAÚ, Município de Silva Jardim, Rio de Janeiro, BrasiL ${ }^{1}$
}

\author{
Fabrício Alvim Carvalho², João Marcelo Alvarenga Braga ${ }^{3}$ \\ \& Marcelo Trindade Nascimento ${ }^{4}$
}

\begin{abstract}
RESUMO
(Estrutura da comunidade arbórea de fragmentos de floresta atlântica ombrófila submontana na região de Imbaú, município de Silva Jardim, Rio de Janeiro, Brasil) Este trabalho teve por objetivo avaliar a estrutura da comunidade arbórea de cinco fragmentos de floresta ombrófila densa submontana (FODS) na região de Imbaú, município de Silva Jardim, RJ, Brasil. Partiu-se da hipótese de que o processo de fragmentação ocasionou uma redução local na riqueza e diversidade de espécies arbóreas. Em cada fragmento foram alocadas sistematicamente quatro parcelas de $100 \times 5 \mathrm{~m}$. Todas as árvores vivas com DAP $\geq 5,0 \mathrm{~cm}$ foram medidas (DAP e altura) e identificadas. As famílias e espécies mais importantes foram: Meliaceae, Sapindaceae e Fabaceae, e Guarea guidonia e Cupania oblongifolia, respectivamente. Estas espécies não haviam se destacado em outras FODS nesta região. As espécies secundárias iniciais predominaram nos fragmentos, indicando efeitos do processo de fragmentação e que estes se encontram em estádio sucessional secundário. O índice de diversidade de espécies ( $\mathrm{H}^{\prime}$ ) por fragmento variou de 2,88 a 3,62 nats.ind ${ }^{-1}$, próximo a outras FODS secundárias, mas inferior aos valores para FODS maduras e preservadas nesta região. Entretanto, quando os fragmentos foram analisados em conjunto, o remanescente apresentou diversidade $\left(4,01\right.$ nats.ind $\left.^{-1}\right)$ próxima à de áreas preservadas, corroborando a hipótese inicial. Estes resultados indicam que a região de Imbaú ainda detém alta riqueza e diversidade de espécies, com uma flora arbórea peculiar, ressaltando a importância desta área para conservação.
\end{abstract}

Palavras-chave: fragmentação florestal, fitossociologia, riqueza de espécies, diversidade de espécies, conservação.

Abstract

(Tree community structure of submontane atlantic rain forest fragments in Imbaú region, municipality of Silva Jardim, Rio de Janeiro, Brazil) This study aimed to evaluate the structure of the tree community of a submontane atlantic rain forest at the Imbaú region, Silva Jardim, RJ. We tested the hypothesis that forest fragmentation causes a reduction in species richness and diversity in these fragments. Four replicate plots of $100 \times 5 \mathrm{~m}$ were systematically located in each of the five forest fragments. All trees with $\mathrm{DBH} \geq 5 \mathrm{~cm}$ were measured (DBH and height) and identified. The most important families were Meliaceae, Sapindaceae, and Fabaceae. Amongst species, Guarea guidonia and Cupania oblongifolia occurred with high values of importance. These species had not been reported as important species in other fragments already analyzed for the same region. The fragments showed a predominance of early secondary species, as a consequence of forest fragmentation process, and indicating a secondary succession stage. The Shannon diversity index ( $\left.\mathrm{H}^{\prime}\right)$ varied from 2.82 to 3.62 nats.ind $^{-1}$ between fragments, and can be considered within the range found for other secondary Atlantic forests. However, when considered all fragments together, the diversity index was close to values found for mature forests $\left(4.0\right.$ nats.ind $\left.^{-1}\right)$, supporting the initial hypothesis. These results suggest that the Imbaú region still has an expressive species richness and diversity, indicating its importance for conservation of the local woody flora.

Key words: forest structure, forest fragmentation, phytosociology, species richness, species diversity, conservation.

Artigo recebido em 03/2007. Aceito para publicação em 08/2009.

${ }^{1}$ Parte da dissertação de mestrado do primeiro autor

${ }^{2}$ Universidade Estadual do Norte Fluminense (UENF), Centro de Biociências e Biotecnologia, Programa de Pós-graduação em Biociências e Biotecnologia, Av. Alberto Lamego 2000, Pq. Califórnia, 28013-620, Campos dos Goytacazes, RJ. fabricio.alvim@gmail.com

${ }^{3}$ Instituto de Pesquisas Jardim Botânico do Rio de Janeiro. R. Pacheco Leão 915. 22460-030. Rio de Janeiro, RJ, Brasil. jmabraga@jbrj.gov.br

${ }^{4}$ Universidade Estadual do Norte Fluminense (UENF), Centro de Biociências e Biotecnologia, Lab. Ciências Ambientais, Av. Alberto Lamego 2000, Pq. Califórnia, 28013-620, Campos dos Goytacazes, RJ. mtn@uenf.br 


\section{INTRODUÇão}

A floresta atlântica brasileiraé um dos biomas mais ameaçados do planeta, sendo apontada como um dos cinco mais importantes hotspots mundiais de biodiversidade (Myers et al. 2000). A principal ameaça a este bioma é a destruição e fragmentação das suas florestas. Segundo Dean (1996), as causas da destruição ao longo dos últimos séculos foram a sobre-exploração dos recursos florestais (madeira, lenha, frutos e caça) e o desmatamento para o uso da terra para agricultura e agropecuária. Estima-se que a cobertura florestal esteja reduzida a menos de $7 \%$ de sua extensão original (Fundação SOS Mata Atlântica 2002). Por isto, a fragmentação da floresta atlântica é apontada como um dos maiores problemas de conservação no Brasil (Tabarelli et al. 2005). Embora seja uma das regiões da América do Sul com o maior número de áreas de proteção legal (Tabarelli et al. 2005), a floresta atlântica brasileira continua sob constante ameaça, pois estas áreas representam não mais que $2 \%$ de todo o bioma restante, e a maioria dos remanescentes florestais permanecem em propriedades privadas à mercê de perturbações antrópicas (Fundação SOS Mata Atlântica 2002; Tabarelli et al. 2005).

No estado do Rio de Janeiro, a floresta atlântica que outrora cobria toda a sua extensão encontra-se hoje reduzida a menos de $20 \%$ da cobertura original, estando os grandes remanescentes em sua maioria sobre áreas montanhosas e inadequadas a agricultura e agropecuária (Fundação SOS Mata Atlântica 2002). As florestas da região costeira do centro-norte fluminense, reconhecidas pela alta diversidade e endemismos da fauna e flora (MMA 2000), durante séculos foram alvo de intensa exploração dos recursos naturais, intensificada nas últimas sete décadas pela substituição de suas florestas por áreas agrícolas e pelo processo de urbanização desordenada (Dean 1996). A paisagem atual desta região encontra-se muito fragmentada, com pequenas manchas florestais isoladas e alteradas em sua maioria, circundadas por extensas matrizes antrópicas como pastos, monoculturas e áreas de desenvolvimento urbano (Fundação SOS Mata Atlântica 2002; Kierulff et al. 2005; Procópio de Oliveira et al. 2008).

O processo de fragmentação florestal é prejudicial para as comunidades vegetais remanescentes. Além da redução na área original dos habitats, diversos estudos evidenciam efeitos diretos (ex. alteração do micro-clima, aumento na intensidade e exposição a ventos, aumento na incidência de insetos e patógenos) e indiretos (ex. alterações nos processos de polinização, dispersão, herbivoria e predação), que comprometem substancialmente os padrões estruturais e ecológicos das comunidades vegetais remanescentes (Laurance \& Bierregaard 1997; Rambaldi \& Oliveira 2005) e apresentam como maior consequência a perda da biodiversidade (Tilman et al. 1994; Turner et al. 1996).

Estudos florísticos e fitossociológicos em fragmentos de florestas ombrófilas da bacia do rio São João, na região centro-norte fluminense, indicam que estes ainda guardam altos níveis de diversidade arbórea (Neves 1999; Borém \& Ramos 2001; Borém \& Oliveira-Filho 2002; Rodrigues 2004; Guedes-Bruni et al. 2006a, b; Pessoa \& Oliveira 2006; Carvalho et al. 2006; Carvalho et al. 2007, Carvalho et al. 2008). Entretanto, a simples presença desses fragmentos não garante a conservação da comunidade original, visto o conjunto de efeitos diretos e indiretos provocados pela fragmentação. Alguns estudos com foco sobre os efeitos da fragmentação florestal nesta região indicam alterações ecológicas nas comunidades arbóreas, tais como a redução na riqueza e diversidade local de espécies (Rodrigues 2004; Carvalho et al. 2007), aumento na riqueza e abundância de espécies associadas a estádios sucessionais iniciais (pioneiras e secundárias iniciais) (Pessoa 2003; Carvalho et al. 2006; Carvalho et al. 2007), e mudanças estruturais através da redução no número de árvores de grande porte e da área basal total, e aumento da densidade de árvores mortas (Pessoa 2003; Rodrigues 2004; Carvalho et al. 2007).

Entre estes estudos, poucos foram realizados nos fragmentos florestais de propriedades privadas, as quais representam a maior porção 
de florestas remanescentes e ao mesmo tempo mais susceptíveis aos impactos antrópicos (Fernandes et al. 2008; Procópio de Oliveira et al. 2008). Nesta situação encontra-se a região de Imbaú, no município de Silva Jardim, que ainda preserva diversos remanescentes de floresta Atlântica importantes como habitats de várias espécies da fauna silvestre, inclusive de grupos de micos-leões-dourado (Leontopithecus rosalia (Linnaeus, 1744)) reintroduzidos e silvestres (MMA 2000; Kierulff et al. 2005; Fernandes et al. 2008; Procópio de Oliveira et al. 2008). Assim, este trabalho teve por objetivo principal analisar a estrutura da comunidade arbórea de fragmentos florestais de floresta ombrófila densa submontana (FODS) localizados em propriedades privadas na região de Imbaú, e compará-los com outros fragmentos florestais da região. Estes fragmentos, que formavam um contínuo florestal, são resultantes do processo de fragmentação iniciado a mais de 50 anos na região. Desta forma, com o intuito de avaliar a contribuição destes fragmentos para a manutenção da riqueza florística desta região, testou-se a hipótese de que o processo de fragmentação ocasionou redução local na riqueza e diversidade de espécies arbóreas.

Ressalta-se que os remanescentes florestais desta região estão totalmente inseridos no Corredor Ecológico da Serra do Mar (ou Corredor Sul da Mata Atlântica), área de extrema importância ecológica e conservacionista por deter a maior extensão contínua de floresta Atlântica dos estados do Rio de Janeiro, São Paulo e Paraná (Ayres et al. 2005). Neste contexto, as informações aqui geradas serão de grande valia para a adoção de estratégias conservacionistas nesta porção do corredor.

\section{Material e Métodos}

\section{Área de estudo}

Localizado na região centro-norte fluminense, o município de Silva Jardim ainda mantém mais de $30 \%$ (ca. de $340 \mathrm{~km}^{2}$ ) de sua cobertura de floresta Atlântica (Fundação SOS Mata Atlântica 2002). O apelo para a preservação de sua cobertura florestal, através do uso do mico-leão-dourado (Leontopithecus rosalia) como espécie bandeira, resultou na criação da primeira Reserva Biológica brasileira, a Reserva Biológica de Poço das Antas, em 1974 (Kierulff et al.2005). Hoje o município de Silva Jardim destaca-se no cenário nacional por ser a região com o maior número de Unidades de Conservação (UC) do Brasil, com mais de uma dezena de Reservas Particulares do Patrimônio Natural (RPPN) implementadas (Fernandes et al. 2008). Apesar disto, ainda existe grande necessidade de criação de novas UCs para a proteção de porção significativa da cobertura florestal natural do município (Fernandes et al. 2008).

A região de Imbaú está localizada no município de Silva Jardim, RJ (42 $28^{\circ} \mathrm{W}$ e $\left.22^{\circ} 37^{\prime} \mathrm{S}\right)$, inserida na Área de Proteção Ambiental da Bacia do Rio São João/MicoLeão-Dourado (Primo \& Völker 2003). Importante por ser área endêmica de ocorrência do mico-leão-dourado (Leontopithecus rosalia), a região de Imbaú ainda preserva alguns remanescentes de floresta Atlântica, porém fragmentados e de tamanhos reduzidos, com poucos excedendo 1000 ha.

Os remanescentes estudados na região de Imbaú formavam uma cobertura florestal contínua, fragmentada a partir do início do século passado para a implantação de agropecuária extensiva. Cinco fragmentos florestais estudados compõem estes remanescentes: "Fazenda Afetiva-Jorge" (AFT - 19 ha), "Fazenda Estreito" (EST - 21 ha), "Fazenda Imbaú" (IMB - 130 ha), "Fazenda Andorinhas" (AND - 145 ha) e "Sítio do Professor" (STP - 155 ha). Estes fragmentos encontram-se isolados há pelo menos 50 anos, embora muito próximos uns dos outros, com distância máxima de cerca de 2 km (Fig. 1). Estão imersos em uma matriz antrópica composta quase que exclusivamente por pastagens, além de pequenas culturas de subsistência (frutas cítricas e coco) e algumas áreas de regeneração natural (capoeiras).

Os solos dos fragmentos são classificados como latossolo amarelo distrófico, com exceção do fragmento EST que apresenta solo hidromórfico (gleissolo) (Lima et al. 2007). A vegetação predominante é a floresta ombrófila 


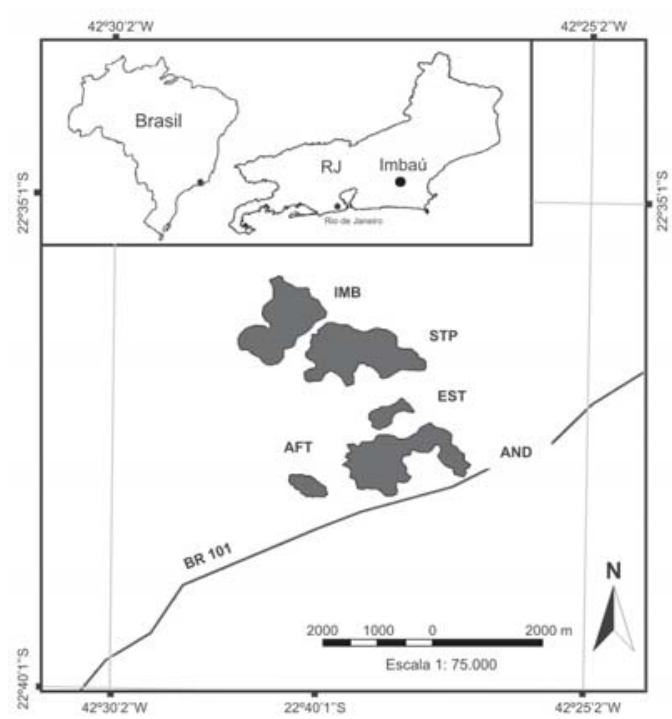

Figura 1 - Mapa com a localização geográfica dos fragmentos de floresta ombrófila densa submontana estudados na região de Imbaú, município de Silva Jardim, RJ. Fragmentos: AFT - Fazenda Afetiva (19 ha); EST Fazenda Estreito (21 ha); IMB - Fazenda Imbaú (130 ha); AND - Fazenda Andorinhas (145 ha); STP - Sítio do Professor (155 ha).

Figure 1 - Geographic location of submountane ombrophilous dense forest fragments at Imbaú region, municipality of Silva Jardim, RJ, Brazil. Forest fragments: AFT - Afetiva farm (19 ha); EST - Estreito farm (21 ha); IMB - Imbaú farm (130 ha); AND - Andorinhas farm (145 ha); STP - Sítio do Professor (155 ha).

densa submontana, segundo classificação de Veloso et al. (1991). O clima da região é enquadrado pela classificação de Köppen no tipo As (tropical chuvoso com estação seca no inverno). A precipitação anual oscila entre 1500 e $2000 \mathrm{~mm}$, sendo os meses de novembro a março os mais chuvosos e de maiores temperaturas (Primo \& Völker 2003).

\section{Análise da vegetação}

Em cada fragmento foram alocadas sistematicamente quatro parcelas de $100 \times 5 \mathrm{~m}$ no sentido norte-sul, cada uma distante $100 \mathrm{~m}$ da outra e $30 \mathrm{~m}$ das bordas, resultando em uma área amostral de 0,2 ha por fragmento e total de 1,0 ha nos remanescentes. O método de parcelas longitudinais foi utilizado visando a obtenção de uma maior heterogeneidade florística (Causton 1988).

Dentro das parcelas, todas as árvores vivas (exceto lianas) com DAP (diâmetro a altura do peito $=1,30 \mathrm{~cm}$ do solo) $\geq 5,0 \mathrm{~cm}$ foram amostradas e medidas quanto ao DAP e à altura. Amostras de material botânico (fértil e/ou estéril) foram coletadas para identificações realizadas no herbário do Instituto de Pesquisas Jardim Botânico do Rio de Janeiro (RB). O material coletado encontra-se depositado no herbário do Centro de Biociências \& Biotecnologia da UniversidadeEstadual do Norte Fluminense(UENF), e duplicatas foram enviadas para o herbário RB. O sistema de classificação adotado foi o APG II (2003). A listagem florística completa destes fragmentos encontra-se em Carvalho et al. (2006).

A similaridade de espécies entre os fragmentos foi estimada através dos índices de Sørensen e Morisita (mod. Horn) (Brower \& Zar 1984). Estes índices foram adotados para a comparação da similaridade qualitativa (presença/ ausência) e quantitativa (densidade) de espécies entre os fragmentos. O programa MVSP (Kovach 2004) foi utilizado para as análises.

O índice de diversidade de espécies de Shannon-Wiener (H') e o índice de equabilidade de Pielou (J) foram calculados segundo Brower \& Zar (1984). Os parâmetros fitossociológicos calculados para as espécies foram: número de indivíduos (Ni), área basal total ( $\mathrm{AB}$ ) e por espécie (Abi), densidade relativa(DR), dominância relativa (DoR) e valor de cobertura (VC) (MuellerDombois \& Ellenberg 1974).

Para a avaliação das características sucessionais, as espécies foram classificadas de acordo com suas características ecológicas em: pioneiras $(\mathrm{Pi})$, secundárias iniciais $(\mathrm{Si})$ e secundárias tardias (St), segundo proposto por Gandolfi et al. (1995). Esta classificação foi baseada em diversos trabalhos realizados em florestas do domínio da floresta Atlântica e observações de campo dos autores.

\section{Resultados}

\section{Similaridade entre os fragmentos}

A similaridade qualitativa de espécies entre os fragmentos foi baixa, com os valores do índice de Jaccard inferiores a 0,35 (Fig. 2a), mesmo entre fragmentos muito próximos e sob condições topográficas, edáficas e climáticas semelhantes. 
Esta baixa similaridade qualitativa está relacionada à alta heterogeneidade florística encontrada, onde apenas 12 espécies (7,1\% do total) foram comuns aos cinco fragmentos (Tab. 1), e 98 (58,3\% do total) ocorreram restritas a um único fragmento.

No entanto, quando considerada a densidade das espécies através da análise quantitativa pelo índice de Morisita, a similaridade entre os fragmentos foi alta, variando de 0,38 a 0,79 (Fig. $2 b)$, indicando que a estrutura da comunidade é um fator agregador. O dendrograma de similaridade pelo índice de Morisita distinguiu dois blocos florísticos, um formado pelos fragmentos AFT e AND, e o outro formado por EST, IMB e STP (Fig. 2b).

Na Tabela 1 observa-se que das 12 espécies comuns aos cinco fragmentos, quase todas ocorreram com elevado número de indivíduos em pelo menos dois fragmentos, e a combinação destas densidades proporcionou uma maior similaridade florística entre determinados fragmentos. Além disso, os fragmentos que formaram os diferentes blocos apresentaram estruturas fitossociológicas semelhantes, conforme descrito a seguir.

\section{Fitossociologia}

Nos fragmentos que formaram o primeiro bloco florístico (AFT e AND, Fig. 2b), AFT apresentou 10 espécies $(15,1 \%$ do total) que foram responsáveis por mais da metade da densidade e dominância relativa, sendo estas: Cupania oblongifolia, Apuleia leiocarpa, Guatteria candolleana, Plathymenia foliolosa, Helicostylis tomentosa, Lacistema pubescens, Ocotea aniboides, Siparuna guianensis, Guapira nitida e Himatanthus lancifolius (Tab. 2). Seguindo o mesmo padrão, no fragmento AND foram registradas, além de Cupania oblongifolia, Plathymenia foliolosa, Guapira nitida, Siparuna guianensis e Apuleia leiocarpa, outras três espécies, Sorocea guilleminiana, Guarea guidonia e Brosimum guianense que representaram apenas $9 \%$ do total de espécies, mas foram responsáveis por metade do número de indivíduos e mais da metade da dominância relativa (Tab. 2).
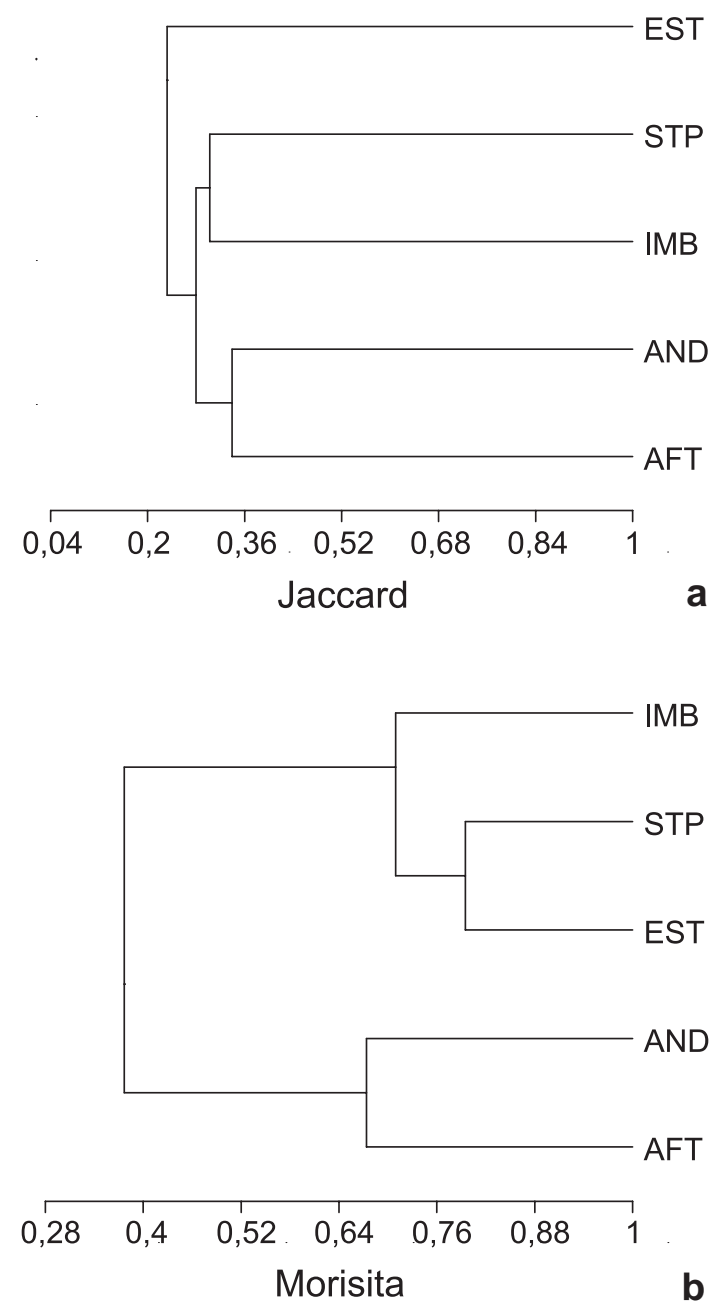

Figura 2 - Dendrogramas de similaridade de espécies entre os fragmentos florestais da região de Imbaú, Silva Jardim, RJ, a partir dos índices de (a) Jaccard e (b) Morisita (mod. Horn).

Figure 2 - Dendrograms of species similarity of forest fragments at Imbaú region, municipality of Silva Jardim, RJ, Brazil. Index: (a) Jaccard and (b) Morisita (mod. Horn).

Os fragmentos que formaram o outro bloco florístico (EST, IMB e STP, Fig. 2b) apresentaram elevadas densidades de Guarea guidonia, que por sua vez foi a espécie que apresentou os mais altos valores de densidade e dominância relativa (Tab. 3). No fragmento EST, esta única espécie acumulou $37 \%$ do total de indivíduos e aproximadamente $60 \%$ da dominância relativa (Tab. 3). No fragmento IMB, além de Guarea guidonia, outras quatro espécies, Plathymenia foliolosa, Xylopia 
Tabela 1 - Densidade das 12 espécies arbóreas comuns aos cinco fragmentos florestais estudados da região de Imbaú, Silva Jardim, RJ. Valores finais indicam a contribuição (\%) destas espécies na densidade total das comunidades de cada fragmento. Classificação sucessional (CS): pioneira (Pi), secundária inicial ( $\mathrm{Si}$ ) e secundária tardia (St). Fragmentos: Fazenda Afetiva (AFT); Fazenda Estreito (EST); Fazenda Imbaú (IMB); Fazenda Andorinhas (AND); Sítio do Professor (STP). n: número total de indivíduos amostrados.

Table 1 - Density of the 12 common tree species in the five forest fragments at Imbaú region, municipality of Silva Jardim, RJ, Brazil. Final values are the contribution (\%) of the species for the total density of each fragment community. Successional classification (CS): pioneer (Pi), early secondary (Si) and late secondary (St). Forest fragments: Afetiva farm (AFT); Estreito farm (EST); Imbaú farm (IMB); Andorinhas farm (AND); Sítio do Professor (STP). n: total density.

\begin{tabular}{llccccc}
\hline Espécie & CS & $\begin{array}{c}\text { AFT } \\
(\mathrm{n}=371)\end{array}$ & $\begin{array}{c}\text { EST } \\
(\mathrm{n}=212)\end{array}$ & $\begin{array}{c}\text { IMB } \\
(\mathrm{n}=307)\end{array}$ & $\begin{array}{c}\text { AND } \\
(\mathrm{n}=428)\end{array}$ & $\begin{array}{c}\text { STP } \\
(\mathrm{n}=280)\end{array}$ \\
\hline Casearia sylvestris Sw. & $\mathrm{Si}$ & 2 & 1 & 10 & 5 & 15 \\
Cupania oblongifolia Mart. & $\mathrm{Si}$ & 47 & 15 & 21 & 40 & 23 \\
Guapira nitida (Mart. ex J.A.Schmidt) Lundell. & $\mathrm{Si}$ & 15 & 5 & 5 & 26 & 3 \\
Guarea guidonia (L.) Sleumer & $\mathrm{Si}$ & 4 & 79 & 52 & 24 & 61 \\
Lacistema pubescens Mart. & $\mathrm{Si}$ & 21 & 3 & 27 & 10 & 3 \\
Luehea divaricata Mart. & $\mathrm{Pi}$ & 8 & 1 & 2 & 3 & 3 \\
Luehea grandiflora Mart. \& Zucc. & $\mathrm{Pi}$ & 4 & 5 & 2 & 2 & 3 \\
Nectandra oppositifolia Nees. & $\mathrm{Si}$ & 11 & 6 & 8 & 3 & 1 \\
Nectandra puberula (Schott) Nees & $\mathrm{Si}$ & 1 & 1 & 13 & 3 & 8 \\
Plathymenia foliolosa Benth. & $\mathrm{St}$ & 4 & 1 & 15 & 8 & 8 \\
Siparuna guianensis (Tul.) A.DC. & $\mathrm{Si}$ & 21 & 5 & 14 & 26 & 9 \\
Xylopia sericea A. St.-Hil. & $\mathrm{Pi}$ & 5 & 4 & 35 & 2 & 1 \\
\hline Contribuição $\%$ do total de indivíduos & - & 38,5 & 59,2 & 66,4 & 35,5 & 49,3 \\
\hline
\end{tabular}

sericea, Cupania oblongifolia e Lacistema pubescens, que representaram apenas $8 \%$ das espécies amostradas, foram responsáveis por metade da densidade e dominância relativa (Tab. 3). Já no STP, o conjunto formado por Guarea guidonia, Plathymenia foliolosa, Cupania oblongifolia e Cariniana legalis, apesar de representar apenas 7\% das espécies e $34 \%$ do total de indivíduos, foi responsável por mais da metade da dominância relativa, o que está relacionado à elevada área basal de seus indivíduos, exceto para Cupania oblongifolia (Tab. 3).

\section{Diversidade}

Os valores do índice de diversidade de espécies de Shannon (H') variaram de 2,88 a 3,62 nats.ind $^{-1}$, enquanto os valores de equabilidade (J) variaram de 0,75 a 0,86 entre os fragmentos
(Tab. 4). O fragmento EST, com o menor número de espécies (46 espécies), apresentou também a maior densidade relativa de uma única espécie (Guarea guidonia), contribuindo para um menor valor de diversidade $\left(\mathrm{H}^{\prime}=2,88\right.$ nats.ind $\left.{ }^{-1}\right)$ e equabilidade $(\mathrm{J}=0,75)$. No outro extremo, os fragmentos AFT e AND foram os que apresentaram a maior diversidade $\left(\mathrm{H}^{\prime}\right.$ $=3,62$ nats.ind $\left.^{-1}\right)$, contribuindo para isto tanto a maior riqueza de espécies (66 e 76 espécies, respectivamente), quanto a menor dominância das principais espécies, resultando em maiores valores de equabilidade ( $\mathrm{J}=0,86$ e 0,84 , respectivamente). Estes valores de diversidade de espécies foram próximos aos registrados para outras FODS secundárias, porém mais baixos quando comparados aos de outras FODS maduras na região centro-norte fluminense, que ultrapassam 4,20 nats.ind ${ }^{-1}$ (Tab. 4). No 
Tabela 2 - Parâmetros fitossociológicos das principais espécies nos fragmentos Fazenda Afetiva (AFT) e Fazenda Andorinhas (AND), região de Imbaú, Silva Jardim, RJ. Espécies ordenadas segundo o valor de cobertura. Classificação sucessional (CS): pioneira (Pi), secundária inicial ( $\mathrm{Si}$ ) e secundária tardia (St). Ni: número de indivíduos; DR: densidade relativa; DoR: dominância relativa; VC: valor de cobertura.

Table 2 - Phytosociological parameters of the most important species in the fragments Afetiva farm (AFT) and Andorinhas farm (AND), at Imbaú region, municipality of Silva Jardim, RJ, Brazil. Species ordered by highest cover values. Successional classification (CS): pioneer (Pi), early secondary ( $\mathrm{Si}$ ) and late secondary (St). Ni: number of individuals; DR: relative density; DoR: relative dominance; VC: cover value.

\begin{tabular}{|c|c|c|c|c|c|}
\hline Espécie & CS & $\mathbf{N i}$ & DR & DoR & $\mathrm{VC}$ \\
\hline \multicolumn{6}{|c|}{ Fazenda Afetiva (AFT) } \\
\hline Cupania oblongifolia Mart. & $\mathrm{Si}$ & 47 & 12,7 & 6,9 & 19,6 \\
\hline Apuleia leiocarpa (Vogel) J.F. Macbr. & $\mathrm{Si}$ & 15 & 4,0 & 11,8 & 15,8 \\
\hline Guatteria candolleana Schlecht. & $\mathrm{Si}$ & 12 & 3,2 & 7,7 & 10,9 \\
\hline Plathymenia foliolosa Benth. & St & 4 & 1,1 & 8,9 & 10,0 \\
\hline Helicostylis tomentosa (Poepp. \& End1.) Rusby & $\mathrm{Si}$ & 22 & 5,9 & 3,6 & 9,5 \\
\hline Lacistema pubescens Mart. & $\mathrm{Si}$ & 20 & 5,4 & 1,9 & 7,3 \\
\hline Siparuna guianensis (Tul.) A.DC. & $\mathrm{Si}$ & 21 & 5,7 & 1,4 & 7,1 \\
\hline Ocotea aniboides $\mathrm{Mez}$ & $\mathrm{St}$ & 13 & 3,5 & 3,0 & 6,5 \\
\hline Guapira nitida (Mart. ex J.A.Schmidt) Lundell. & $\mathrm{Si}$ & 15 & 4,0 & 2,3 & 6,3 \\
\hline Eugenia stigmatosa DC. & St & 4 & 1,1 & 4,9 & 6,0 \\
\hline Himatanthus lancifolius (Müll. Arg.) Woodson & $\mathrm{St}$ & 11 & 3,0 & 2,9 & 5,9 \\
\hline Guapira opposita (Vell.) Reitz & $\mathrm{Si}$ & 11 & 3,0 & 2,8 & 5,8 \\
\hline Euterpe edulis Mart. & $\mathrm{St}$ & 17 & 4,6 & 1,1 & 5,7 \\
\hline Luehea divaricata Mart. & $\mathrm{Pi}$ & 8 & 2,2 & 3,1 & 5,3 \\
\hline Machaerium brasiliensis Vog. & $\mathrm{Si}$ & 4 & 1,1 & 3,9 & 5,0 \\
\hline Bathysa mendoncaei K. Schum. & $\mathrm{St}$ & 10 & 2,7 & 1,8 & 4,5 \\
\hline Cabralea canjerana (Vell.) Mart. & $\mathrm{Si}$ & 8 & 2,2 & 2,1 & 4,3 \\
\hline Nectandra oppositifolia Nees. & $\mathrm{Si}$ & 11 & 3,0 & 1,0 & 4,0 \\
\hline Pseudopiptadenia contorta (DC.) G.P. Lewis \& M.P. Lima & $\mathrm{Pi}$ & 3 & 0,8 & 3,2 & 4,0 \\
\hline Astrocaryum aculeatissimum (Schott) Burret & $\mathrm{Pi}$ & 6 & 1,6 & 2,3 & 3,9 \\
\hline Outras 46 & & 109 & 129,2 & 23,4 & 52,6 \\
\hline \multicolumn{6}{|c|}{ Fazenda Andorinhas (AND) } \\
\hline Cupania oblongifolia Mart. & $\mathrm{Si}$ & 40 & 9,3 & 11,4 & 20,7 \\
\hline Sorocea guilleminiana Gaudich. & $\mathrm{Si}$ & 37 & 8,6 & 9,1 & 17,7 \\
\hline Guarea guidonea (L.) Sleumer & $\mathrm{Si}$ & 24 & 5,6 & 9,2 & 14,8 \\
\hline Plathymenia foliolosa Benth. & St & 8 & 1,9 & 10,9 & 12,8 \\
\hline Brosimum guianense (Aubl.) Huber & $\mathrm{Si}$ & 32 & 7,5 & 4,4 & 11,9 \\
\hline Guapira nitida (Mart. ex J.A.Schmidt) Lundell. & $\mathrm{Si}$ & 26 & 6,1 & 2,3 & 8,4 \\
\hline Apuleia leiocarpa (Vogel) J.F. Macbr. & $\mathrm{Si}$ & 12 & 2,8 & 4,7 & 7,5 \\
\hline Siparuna guianensis (Tul.) A.DC. & $\mathrm{Si}$ & 26 & 6,1 & 1,4 & 7,5 \\
\hline Helicostylis tomentosa (Poepp. \& Endl.) Rusby & $\mathrm{Si}$ & 16 & 3,7 & 3,4 & 7,1 \\
\hline Psychotria velloziana Benth. & $\mathrm{Si}$ & 22 & 5,1 & 1,6 & 6,7 \\
\hline Bathysa mendoncaei K. Schum. & $\mathrm{St}$ & 9 & 2,1 & 4,2 & 6,3 \\
\hline Lacistema pubescens Mart. & $\mathrm{Si}$ & 10 & 2,3 & 1,7 & 4,0 \\
\hline Guapira opposita (Vell.) Reitz & $\mathrm{Si}$ & 13 & 3 & 1 & 4,0 \\
\hline Tabernaemontana catharinensis A.DC. & St & 8 & 1,9 & 1,9 & 3,8 \\
\hline Persea americana Mill. & $\mathrm{Ni}$ & 9 & 2,1 & 1,5 & 3,6 \\
\hline Sparattosperma leucanthum (Vell.) K. Schum. & $\mathrm{Pi}$ & 2 & 0,5 & 3 & 3,5 \\
\hline
\end{tabular}




\begin{tabular}{llllll}
\hline Espécie & CS & Ni & DR & DoR & VC \\
\hline Alchornea glandulosa Poepp. & & & & & \\
Tapirira guianensis Aubl. & $\mathrm{Si}$ & 6 & 1,4 & 2 & 3,4 \\
Cybistax antisyphilitica (Mart.) Mart. & $\mathrm{Pi}$ & 7 & 1,6 & 1,2 & 2,8 \\
Astronium graveolens Jacq. & $\mathrm{Si}$ & 5 & 1,2 & 1,6 & 2,8 \\
Outras 39 & - & 113 & 26,5 & 21,4 & 47,9 \\
\hline
\end{tabular}

Tabela 3 - Parâmetros fitossociológicos das principais espécies nos fragmentos Fazenda Estreito (EST), Fazenda Imbaú (IMB) e Sítio do Professor (STP), região de Imbaú, Silva Jardim, RJ. Espécies ordenadas segundo o valor de cobertura. Classificação sucessional (CS): pioneira (Pi), secundária inicial $(\mathrm{Si})$ e secundária tardia $(\mathrm{St})$. Ni: número de indivíduos; DR: densidade relativa; DoR: dominância relativa; VC: valor de cobertura.

Table 3 - Phytosociological parameters of the most important species from the fragments Estreito farm (EST), Imbaú farm (IMB) and Sítio do Professor (STP), at Imbaú region, municipality of Silva Jardim, RJ, Brazil. Species ordered by highest cover values. Successional classification (CS): pioneer (Pi), early secondary (Si) and late secondary (St). Ni: number of individuals; DR: relative density; DoR: relative dominance; VC: cover value.

\begin{tabular}{|c|c|c|c|c|c|}
\hline Espécie & CS & $\mathbf{N i}$ & DR & DoR & $\mathbf{V C}$ \\
\hline \multicolumn{6}{|c|}{ Fazenda Estreito (EST) } \\
\hline Guarea guidonia (L.) Sleumer & $\mathrm{Si}$ & 79 & 37,3 & 57,9 & 95,2 \\
\hline Alchornea glandulosa Poepp. & $\mathrm{Si}$ & 8 & 3,8 & 8,5 & 12,3 \\
\hline Cupania oblongifolia Mart. & $\mathrm{Si}$ & 15 & 7,1 & 2,7 & 9,8 \\
\hline Platymiscium floribundum Vog. & St & 5 & 2,4 & 5,2 & 7,6 \\
\hline Luehea grandiflora Mart. \& Zucc. & $\mathrm{Pi}$ & 5 & 2,4 & 2,8 & 5,2 \\
\hline Plathymenia foliolosa Benth. & St & 1 & 0,5 & 4,3 & 4,8 \\
\hline Tabernaemontana catharinensis A.DC. & St & 5 & 2,4 & 1,6 & 4,0 \\
\hline Nectandra oppositifolia Nees. & $\mathrm{Si}$ & 6 & 2,8 & 0,9 & 3,7 \\
\hline Miconia prasina (Sw.) DC. & $\mathrm{Pi}$ & 7 & 3,3 & 0,4 & 3,7 \\
\hline Miconia holosericea (L.) DC. & $\mathrm{Pi}$ & 6 & 2,8 & 0,5 & 3,3 \\
\hline Guatteria candolleana Schlecht. & $\mathrm{Si}$ & 5 & 2,4 & 0,9 & 3,3 \\
\hline Cecropia glaziovii Snethl. & $\mathrm{Pi}$ & 5 & 2,4 & 0,7 & 3,1 \\
\hline Trichilia lepidota $\mathrm{Sw}$. & St & 2 & 0,9 & 1,9 & 2,8 \\
\hline Cecropia hololeuca Miq. & $\mathrm{Pi}$ & 2 & 0,9 & 1,9 & 2,8 \\
\hline Siparuna guianensis (Tul.) A.DC. & $\mathrm{Si}$ & 5 & 2,4 & 0,4 & 2,8 \\
\hline Guapira nitida (Mart. ex J.A.Schmidt) Lundell. & $\mathrm{Si}$ & 5 & 2,4 & 0,4 & 2,8 \\
\hline Xylopia sericea A. St.-Hil. & $\mathrm{Pi}$ & 4 & 1,9 & 0,5 & 2,4 \\
\hline Inga edulis Mart. & $\mathrm{Pi}$ & 3 & 1,4 & 1,0 & 2,4 \\
\hline Acacia polyphylla Benth. & $\mathrm{Si}$ & 1 & 0,5 & 1,7 & 2,2 \\
\hline Psychotria velloziana Benth. & $\mathrm{Si}$ & 4 & 1,9 & 0,2 & 2,1 \\
\hline Outras 26 & - & 39 & 18,1 & 5,6 & 23,7 \\
\hline \multicolumn{6}{|c|}{ Fazenda Imbaú (IMB) } \\
\hline Guarea guidonia $($ L.) Sleumer & $\mathrm{Si}$ & 53 & 17,3 & 22,1 & 39,4 \\
\hline Plathymenia foliolosa Benth. & St & 15 & 4,9 & 22,5 & 27,4 \\
\hline Xylopia sericea A. St.-Hil. & $\mathrm{Pi}$ & 35 & 11,4 & 7,3 & 18,7 \\
\hline Cupania oblongifolia Mart. & $\mathrm{Si}$ & 21 & 6,8 & 6,3 & 13,1 \\
\hline Lacistema pubescens Mart. & $\mathrm{Si}$ & 27 & 8,8 & 1,7 & 10,5 \\
\hline Tibouchina granulosa Cogn. & $\mathrm{Pi}$ & 11 & 3,6 & 3,9 & 7,5 \\
\hline Casearia sylvestris $\mathrm{Sw}$. & $\mathrm{Si}$ & 10 & 3,3 & 2,2 & 5,5 \\
\hline Nectandra puberula (Schott) Nees & $\mathrm{Si}$ & 13 & 4,2 & 1,2 & 5,4 \\
\hline Siparuna guianensis (Tul.) A.DC. & $\mathrm{Si}$ & 14 & 4,6 & 0,8 & 5,4 \\
\hline Guarea macrophylla Vahl & St & 4 & 1,3 & 3,0 & 4,3 \\
\hline Nectandra oppositifolia Nees & $\mathrm{Si}$ & 8 & 2,6 & 0,7 & 3,3 \\
\hline
\end{tabular}




\begin{tabular}{|c|c|c|c|c|c|}
\hline Espécie & CS & $\mathbf{N i}$ & DR & DoR & $\mathrm{VC}$ \\
\hline Cabralea canjerana (Vell.) Mart. & $\mathrm{Si}$ & 3 & 1,0 & 2,3 & 3,3 \\
\hline Lonchocarpus cultratus (Vell.) A.M.G. Azeredo \& H. Lima & St & 2 & 0,7 & 2,6 & 3,3 \\
\hline Miconia cinnamomifolia (DC.) Naudin & $\mathrm{Pi}$ & 4 & 1,3 & 1,8 & 3,1 \\
\hline Alchornea triplinervia (Spreng.) Müll. Arg. & $\mathrm{Si}$ & 4 & 1,3 & 1,7 & 3,0 \\
\hline Alchornea glandulosa Poepp. & $\mathrm{Si}$ & 5 & 1,6 & 1,2 & 2,8 \\
\hline Cecropia hololeuca Miq. & $\mathrm{Pi}$ & 7 & 2,3 & 0,5 & 2,8 \\
\hline Psychotria velloziana Benth. & $\mathrm{Si}$ & 3 & 1,0 & 1,8 & 2,8 \\
\hline Platycyanus regnellii Benth. & St & 4 & 1,3 & 1,4 & 2,7 \\
\hline Protium heptaphyllum (Aubl.) March. & $\mathrm{Si}$ & 5 & 1,6 & 1,0 & 2,6 \\
\hline Outras 56 & - & 59 & 19,1 & 14,0 & 33,1 \\
\hline \multicolumn{6}{|c|}{ Sítio do Professor (STP) } \\
\hline Guarea guidonia $(\mathrm{L}$.$) Sleumer$ & $\mathrm{Si}$ & 61 & 21,8 & 34,6 & 56,4 \\
\hline Plathymenia foliolosa Benth. & St & 8 & 2,9 & 21,9 & 24,8 \\
\hline Cupania oblongifolia Mart. & $\mathrm{Si}$ & 23 & 8,2 & 4,5 & 12,7 \\
\hline Cariniana legalis (Mart.) Kuntze & St & 2 & 0,7 & 7,5 & 8,2 \\
\hline Faramea multiflora A.Rich. ex DC. & St & 17 & 6,1 & 1,3 & 7,4 \\
\hline Casearia sylvestris $\mathrm{Sw}$. & $\mathrm{Si}$ & 15 & 5,4 & 1,4 & 6,8 \\
\hline Nectandra membranacea (SW.) Griseb. & St & 15 & 5,4 & 1,3 & 6,7 \\
\hline Guarea macrophylla Vahl & St & 3 & 1,1 & 5,3 & 6,4 \\
\hline Euterpe edulis Mart. & St & 15 & 5,4 & 1 & 6,4 \\
\hline Nectandra puberula (Schott) Nees & $\mathrm{Si}$ & 8 & 2,9 & 1,6 & 4,5 \\
\hline Luehea conwentizii K.Schum. & $\mathrm{Pi}$ & 9 & 3,2 & 0,7 & 3,9 \\
\hline Pouteria caimito (Ruiz \& Pav.) Radlk. & $\mathrm{St}$ & 2 & 0,7 & 2,7 & 3,4 \\
\hline Siparuna guianensis (Tul.) A.DC. & $\mathrm{Si}$ & 9 & 3,2 & 0,2 & 3,4 \\
\hline Mabea fistulifera Mart. & $\mathrm{Pi}$ & 3 & 1,1 & 2 & 3,1 \\
\hline Luehea grandiflora Mart. \& Zucc. & $\mathrm{Pi}$ & 3 & 1,1 & 1,8 & 2,9 \\
\hline Guapira opposita (Vell.) Reitz & $\mathrm{Si}$ & 6 & 2,1 & 0,7 & 2,8 \\
\hline Platycyanus regnellii Benth. & St & 6 & 2,1 & 0,6 & 2,7 \\
\hline Bauhinia forficata Link. & $\mathrm{Si}$ & 7 & 2,5 & 0,2 & 2,7 \\
\hline Tabernaemontana catharinensis A.DC. & St & 6 & 2,1 & 0,3 & 2,4 \\
\hline Astrocaryum aculeatissimum (Schott) Burret & $\mathrm{Pi}$ & 5 & 1,8 & 0,5 & 2,3 \\
\hline Outras 38 & - & 57 & 20,2 & 9,9 & 30,1 \\
\hline
\end{tabular}

entanto, quando considerado o conjunto dos cinco fragmentos, o índice de diversidade foi de 4,01 nats.ind ${ }^{-1}$ e a equabilidade de 0,88, valores próximos aos encontrados para outras FODS maduras na região (Tab. 4).

\section{Grupos ecológicos}

A distribuição das espécies por grupos ecológicos sucessionais indicou o predomínio das espécies secundárias iniciais no componente arbóreo dos fragmentos estudados (Fig. 3). Espécies secundárias iniciais ocorreram com maior riqueza, densidade e valor de cobertura (VC) em todos os fragmentos, com exceção do fragmento STP, onde as espécies secundárias tardias apresentaram maior riqueza, e ocorreram com densidade e VC semelhante às das secundárias iniciais (Fig. 3).

\section{Distribuição de alturas e diâmetros}

A análise da distribuição por alturas das comunidades arbóreas dos fragmentos, fixas em escalas de $5 \mathrm{~m}$, mostrou maior concentração dos indivíduos até $10 \mathrm{~m}$, com poucos ultrapassando os $20 \mathrm{~m}$ (Fig. 4). As árvores emergentes foram representadas por apenas $1 \%$ dos indivíduos, atingindo altura máxima de $30 \mathrm{~m}$, como encontrado para alguns indivíduos de Guarea guidonia, Plathymenia foliolosa e Cariniana legalis. O histograma de frequência dos indivíduos em classes diamétricas, fixas em escalas de $5 \mathrm{~cm}$, apresentou formato tendendo 

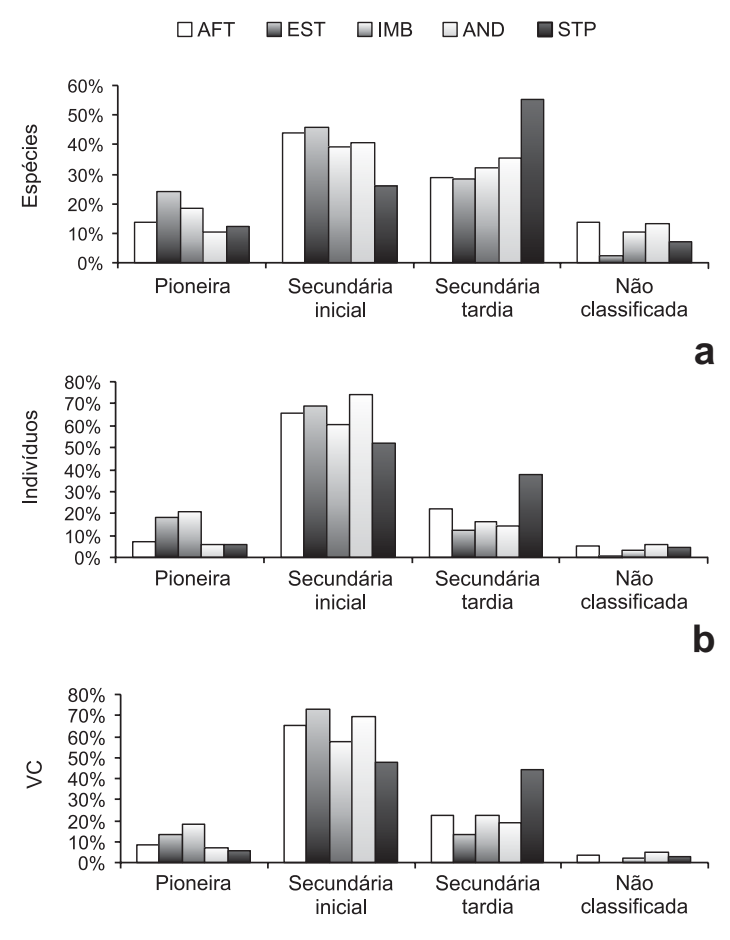

C

Figura 3 - Distribuição da riqueza (a), número de indivíduos (b) e valor de cobertura (c) das espécies arbóreas em grupos ecológicos sucessionais (sensu Gandolfi et al. 1995) nos fragmentos florestais da região de Imbaú, Silva Jardim, RJ. Fragmentos: Fazenda Afetiva (AFT); Fazenda Estreito (EST); Fazenda Imbaú (IMB); Fazenda Andorinhas (AND); Sítio do Professor (STP).

Figure 3 - Distribution of (a) richness, (b) number of individuals and (c) cover value of tree species according to ecological successional groups (sensu Gandolfi et al. 1995) in the forest fragments at Imbaú region, municipality of Silva Jardim, RJ, Brazil. Forest fragments: Afetiva farm (AFT); Estreito farm (EST); Imbaú farm (IMB); Andorinhas farm (AND); Sítio do Professor (STP).

ao J-reverso para todos os fragmentos, indicando um decréscimo acentuado no número de indivíduos no sentido das menores para as maiores classes de diâmetro (Fig. 5).

\section{Discussão}

As análises de similaridade de espécies entre os fragmentos revelaram elevada heterogeneidade florística entre os remanescentes. Estes resultados estão de acordo com outros estudos na floresta atlântica, onde a elevada heterogeneidade florística representa um dos padrões mais claros e conhecidos acerca do bioma (Mori et al. 1981; Mori et al. 1983; Thomaz et al. 1998).

Os fragmentos apresentaram número reduzido de espécies com elevada dominância no ambiente, ou com monodominância em alguns casos, como observado para o fragmento EST onde Guarea guidonia atinge 57,9\% da dominância relativa (Tab. 3). Segundo Hart et al. (1989), a alta dominância em florestas tropicais ocorre, geralmente, em situações de estresse, seja por causas naturais ou por perturbações antrópicas. Assim, a presença de elevada dominância de poucas espécies nos fragmentos estudados, exercida principalmente por espécies secundárias iniciais, como Guarea guidonia e Cupania oblongifolia, deve ser indicativo de perturbação nestas áreas. Tal fato corrobora o padrão observado para outras florestas tropicais secundárias com perturbações antrópicas (Terborgh 1992; Hubbel et al. 1999).

A partir da comparação com a listagem de outros estudos fitossociológicos realizados em florestas ombrófilas submontanas no CentroNorte Fluminense (Guedes-Bruni 1998; Neves 1999; Kurtz \& Araujo 2000; Borém \& Ramos 2001; Borém \& Oliveira-Filho 2002; Moreno et al. 2003; Pessoa 2003; Rodrigues 2004; GuedesBruni et al. 2006 a,b; Pessoa \& Oliveira 2006; Carvalho et al. 2007), observa-se que algumas das principais espécies da região de Imbaú, como Guarea guidonia e Cupania oblongifolia, têm baixa importância na composição estrutural das demais florestas, e até o momento este foi o único local a apresentar Guarea guidonia como a espécie mais importante nas comunidades arbóreas. Em vários destes estudos, foi comum a presença das espécies do gênero Guarea dentre o grupo das consideradas raras (com apenas um indivíduo, sensu Martins 1993). Cupania oblongifolia, por sua vez, foi encontrada entre as mais importantes apenas em uma FODS, no município vizinho de Rio Bonito (Carvalho et al. 2007). No geral, Cupania é um gênero de grande importância na composição estrutural das FODS do centro-norte fluminense, visto que, além da já citada $C$. oblongifolia, outras espécies como $C$. racemosa, $C$. emarginata, $C$. schizoneura e $C$. furfuracea se destacaram em diversas FODS da 
Tabela 4 - Riqueza e diversidade de espécies arbóreas dos fragmentos florestais estudados na região de Imbaú, Silva Jardim, RJ, e comparação com outros trechos de floresta atlântica ombrófila submontana do centro-norte fluminense. DAP: limite de inclusão diamétrica (cm); Área: área amostral (ha) (método de amostragem por parcelas adotado em todos os estudos); S: riqueza de espécies; $\mathrm{H}^{\prime}$ : índice de diversidade de Shannon-Wiener (nats.ind ${ }^{-1}$ ); J: índice de equabilidade de Pielou.

Table 4 - Richness and diversity of tree species in the forest fragments at Imbaú region, municipality of Silva Jardim, RJ, and comparison with other remnants of submountane ombrophilous dense forest fragments from the Northern region of Rio de Janeiro State, Brazil. DAP: diametric inclusion limit (cm); Área: sample area (ha) (plot methods in all studies); S: species richness; H': Shannon-Wiener diversity index (nats.ind $\left.{ }^{-1}\right)$; J: Pielou equability index.

\begin{tabular}{|c|c|c|c|c|c|c|}
\hline Localidade & DAP & Área & $\mathbf{S}$ & $\mathbf{H}^{\prime}$ & $\mathbf{J}$ & Referência \\
\hline Fazenda Afetiva $(\text { AFT })^{1}$ & 5,0 & 0,20 & 66 & 3,62 & 0,86 & Este estudo \\
\hline Fazenda Estreito $(\mathrm{EST})^{1}$ & 5,0 & 0,20 & 46 & 2,88 & 0,75 & Este estudo \\
\hline Fazenda Imbaú (IMB) ${ }^{1}$ & 5,0 & 0,20 & 59 & 3,26 & 0,80 & Este estudo \\
\hline Fazenda Andorinhas (AND) ${ }^{1}$ & 5,0 & 0,20 & 76 & 3,62 & 0,84 & Este estudo \\
\hline Sítio do Professor (STP $)^{1}$ & 5,0 & 0,20 & 58 & 3,26 & 0,81 & Este estudo \\
\hline Total (cinco fragmentos) & 5,0 & 1,00 & 161 & 4,01 & 0,88 & Este estudo \\
\hline REBIO Poço das Antas ${ }^{1}$ & 5,0 & 0,20 & 64 & 3,02 & 0,73 & Pessoa (2003) \\
\hline REBIO Poço das Antas ${ }^{1}$ & 5,0 & 0,50 & 107 & 3,90 & 0,83 & Pessoa (2003) \\
\hline REBIO Poço das Antas ${ }^{1}$ & 5,0 & 0,60 & 151 & 3,65 & 0,73 & Pessoa (2003) \\
\hline REBIO Poço das Antas ${ }^{1}$ & 2,5 & 0,25 & 60 & 3,24 & 0,79 & Neves (1999) \\
\hline REBIO Poço das Antas ${ }^{1}$ & 2,5 & 0,25 & 104 & 3,78 & 0,81 & Neves (1999) \\
\hline REBIO Poço das Antas ${ }^{1}$ & 10,0 & 1,00 & 169 & 4,55 & 0,89 & Guedes-Bruni et al. (2006a) \\
\hline Fazenda Biovert $^{1}$ & 3,2 & 0,36 & 98 & 3,46 & 0,75 & Borém \& Ramos (2001) \\
\hline Fazenda Biovert $^{1}$ & 3,2 & 0,36 & 129 & 4,14 & 0,85 & Borém \& Oliveira-Filho (2002) \\
\hline Fazenda Rio Vermelho ${ }^{2}$ & 5,0 & 0,40 & 106 & 3,91 & 0,84 & Carvalho et al. (2007) \\
\hline REBIO União ${ }^{3 *}$ & 10,0 & 1,20 & 250 & 4,90 & 0,87 & Rodrigues (2004) \\
\hline E.E.E. Paraíso ${ }^{4 *}$ & 10,0 & 1,00 & 131 & 4,40 & 0,91 & Guedes-Bruni (1998) \\
\hline Imbé - $50 \mathrm{~m}^{5 *}$ & 10,0 & 0,60 & 125 & 4,21 & - & Moreno et al. (2003) \\
\hline Imbé - $250 \mathrm{~m}^{5 *}$ & 10,0 & 0,60 & 145 & 4,30 & - & Moreno et al. (2003) \\
\hline
\end{tabular}

Municípios: ${ }^{1}$ Silva Jardim; ${ }^{2}$ Rio Bonito; ${ }^{3}$ Rio das Ostras; ${ }^{4}$ Guapimirim; ${ }^{5}$ Campos dos Goytacazes. / Municipalities: ${ }^{1}$ Silva Jardim; ${ }^{2}$ Rio Bonito; ${ }^{3}$ Rio das Ostras; ${ }^{4}$ Guapimirim; ${ }^{5}$ Campos dos Goytacazes.

*trechos florestais preservados em Unidade de Conservação. / forest remnant preserved in conservation units.

REBIO: Reserva Biológica Federal; E.E.E.: Estação Ecológica Estadual. / REBIO: Federal Biological Reserve; E.E.E.: State Ecological Station.

região (Guedes-Bruni 1998; Neves 1999; Kurtz \& Araujo 2000; Borém \& Ramos 2001; Borém \& Oliveira-Filho 2002; Moreno et al. 2003; Rodrigues 2004; Carvalho et al. 2007).

A elevada proporção de espécies secundárias iniciais (Fig. 3) foi outro indicativo de perturbação pretérita, visto que em florestas tropicais maduras estes grupos tendem a ocorrer em baixas densidades (Hubbel et al. 1999). Assim, os resultados indicam que os fragmentos florestais ainda não alcançaram o estádio maduro, ou que existe algum fator impedindo o desenvolvimento destas comunidades. Dentre os fatores podem ser destacados o próprio processo de fragmentação florestal ocorrido há várias décadas e as constantes intervenções antrópicas que estes fragmentos vêm sofrendo ao longo do tempo, como corte seletivo de madeira e queimadas, principalmente por estarem localizados em propriedades particulares sem a proteção efetiva (Procópio de Oliveira et al. 2008).

Embora os fragmentos da região de Imbaú possam ser considerados secundários, estes apresentaram baixa riqueza e densidade de espécies pioneiras, que contraposto à elevada riqueza e densidade de espécies secundárias iniciais, indicam avanço da sucessão e tendência à maior adequação das condições para o sucesso no recrutamento de espécies tardias, indicando que o componente arbóreo destes fragmentos 


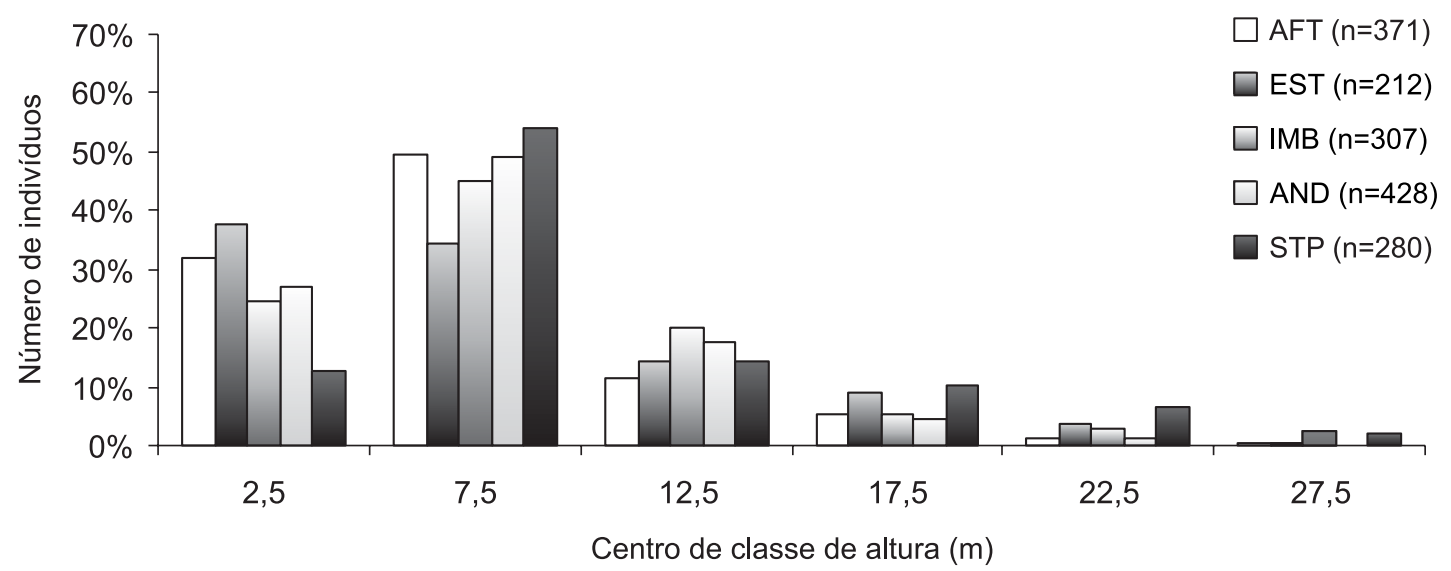

Figura 4 - Distribuição de frequência das classes de altura dos indivíduos arbóreos nos fragmentos florestais da região de Imbaú, Silva Jardim, RJ. Fragmentos: Fazenda Afetiva (AFT); Fazenda Estreito (EST); Fazenda Imbaú (IMB); Fazenda Andorinhas (AND); Sítio do Professor (STP).

Figure 4 - Distribution of trees in height frequency classes in the forest fragments at Imbaú region, municipality of Silva Jardim, RJ, Brazil. Forest fragments: Afetiva farm (AFT); Estreito farm (EST); Imbaú farm (IMB); Andorinhas farm (AND); Sítio do Professor (STP).

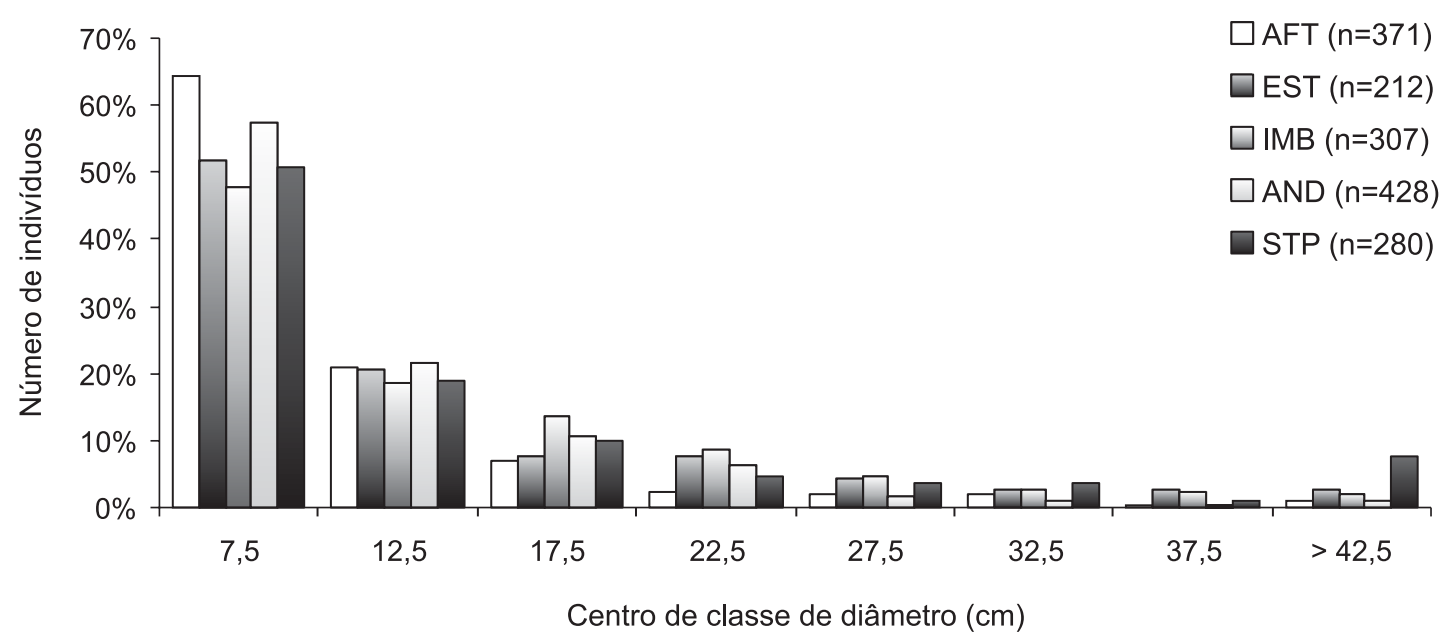

Figura 5 - Distribuição de frequência das classes de diâmetros dos indivíduos arbóreos nos fragmentos florestais da região de Imbaú, Silva Jardim, RJ. Fragmentos: Fazenda Afetiva (AFT); Fazenda Estreito (EST); Fazenda Imbaú (IMB); Fazenda Andorinhas (AND); Sítio do Professor (STP).

Figure 5 - Distribution of trees in diameter frequency classes in the forest fragments at Imbaú region, municipality of Silva Jardim, RJ, Brazil. Forest fragments: Afetiva farm (AFT); Estreito farm (EST); Imbaú farm (IMB); Andorinhas farm (AND); Sítio do Professor (STP).

encontra-se em desenvolvimento para fases mais maduras.

Dentre as tendências observadas quanto à distribuição diamétrica entre os fragmentos, AFT eAND apresentaram o maior número de indivíduos nas classes de menor diâmetro, onde menos de $10 \%$ atingem diâmetros acima dos $20 \mathrm{~cm}$, indicando um processo de regeneração mais recente em relação aos demais. No outro extremo, o fragmento STP apresentou um maior número de indivíduos de grande porte, dos quais muitos ultrapassaram os $40 \mathrm{~cm}$ de diâmetro, indicando um processo de regeneração mais avançado. Estes resultados parecem estar relacionados com o histórico de preservação dos fragmentos, visto que AFT e AND são aqueles que se encontram mais desprotegidos, sem qualquer tipo de barreira para o acesso das pessoas, tornando-os mais 
vulneráveis aos constantes efeitos antrópicos já citados, que por sua vez retardam o processo sucessional (Parrota 1993; Viana et al. 1997).

A proximidade com a rodovia BR-101 consiste em outro agravante para estes fragmentos, que segundo Peixoto \& Costa-Júnior (2004) é um dos fatores mais prejudiciais na conservação das porções marginais das Unidades de Conservação da região, em função do aumento de ocorrência de queimada e corte seletivo de madeira. Ao contrário, o fragmento STPencontrase mais distante da BR-101, mais protegido pelo proprietário e em lugar de mais difícil acesso, o que dificulta a perturbação antrópica no local. Este fragmento também se encontra protegido há mais tempo que os demais, onde o processo de regeneração natural ocorre isento de intervenções antrópicas há pelo menos três décadas, sendo hoje uma Reserva Particular do Patrimônio Natural (RPPN). Neste sentido, conforme sugerido por Matsuo et al. (2008), é muito importante a conscientização dos proprietários e da população do entorno para que a conservação das florestas remanescentes seja efetiva.

A região centro-norte fluminense, especialmente na bacia do rio São João e seus arredores, vêm sendo apontada como detentora de elevada diversidade biológica (MMA 2000). Em termos florísticos, a diversidade de espécies arbóreas registrada para as florestas das Reservas Biológicas de Poço das Antas $\left(\mathrm{H}^{\prime}=4,55\right.$ nats.ind $^{-1}$, Guedes-Bruni 2006a) e União ( $\mathrm{H}^{\prime}=4,90$ nats.ind $^{-1}$, Rodrigues 2004) figuram dentre os mais altos já registrados a floresta Atlântica. Os fragmentos da região de Imbaú, embora enquadrados na mesma fitofisionomia, apresentaram diversidade inferior à destas florestas, provavelmente por serem secundários e por já terem sofrido perturbações que proporcionaram uma redução da riqueza de espécies, representadas pelo processo de fragmentação florestal. Entretanto, quando considerados os cinco fragmentos como um todo (1 ha amostrado), a riqueza (161 espécies) e a diversidade de espécies $\left(\mathrm{H}^{\prime}=4,01\right.$ nats.ind $\left.^{-1}\right)$ aumentam e passam a ser mais próximos aos valores encontrados para outras FODS maduras da região (Tab. 4), indicando que, apesar da constatação de que efeitos antrópicos pretéritos tenha afetado sua estrutura, esta região ainda detém alta riqueza e diversidade na flora arbórea.

Com base nos resultados obtidos concluiuse que os fragmentos estudados são caracterizados pela dominância ecológica de poucas espécies, principalmente por espécies secundárias iniciais, como Guarea guidonia e Cupania oblongifolia, resultando em menor diversidade de espécies quando comparado com outras FODS preservadas da região. Entretanto, o fato do conjunto dos fragmentos estudados demonstrar riqueza e diversidade de espécies próxima a de áreas florestais preservadas da região, reforça a importância da conservação destes fragmentos. A elevada riqueza e densidade de espécies secundárias iniciais em contraste com a baixa riqueza e densidade de espécies pioneiras, associado ao grande número de indivíduos regenerantes, indicam o avanço destas comunidades para estádios sucessionais mais tardios. É importante mencionar que as principais variações estruturais entre os fragmentos parecem estar relacionadas à perturbação antrópica, visto que as áreas em pior estado de conservação são aquelas que se encontram mais desprotegidas pelos proprietários e mais próximas a rodovia BR-101. Desta forma, a ocorrência destes remanescentes e a consequente preservação das espécies neles existentes mostram-se diretamente dependentes de ações efetivas de conservação por parte dos proprietários e órgãos ambientais competentes, a fim de que se diminua ou mesmo se coíba a ocorrência de novos distúrbios antrópicos, permitindo que os processos naturais de sucessão florestal atuem nestes fragmentos.

\section{Agradecimentos}

Agradecemos à Dora M. Villela, Dorothy S. D. Araujo e Pablo J. F. P. Rodrigues pelas contribuições ao manuscrito; aos pesquisadores do Instituto de Pesquisa Jardim Botânico do Rio de Janeiro, Alexandre Quinet, Carine Pinto- 
Quinet, Cláudia M. Vieira, Cyl Farney, Massimo G. Bovini e Haroldo C. de Lima, pelo auxílio na identificação do material botânico; ao Heuzenil S. Cordeiro e Márcio M. Morais pelo auxílio nos trabalhos de campo; ao FNMA/MMA pelo apoio financeiro; ao LCA/CBB/UENF, Associação Mico-Leão-Dourado e IBAMA pelo apoio logístico; a CAPES pela concessão da bolsa de mestrado ao primeiro autor. Ao CNPq pela bolsa de produtividade Científica à MTN .

\section{REFERÊNCIAS BBIBLIOGRÁFICAS}

APG II. 2003. An update of the Angiosperm Phylogeny Group classification of the orders and families of flowering plants: APGII. Botanical Journal of the Linnean Society 141: 399-436.

Ayres, J. M.; Fonseca, G. A. B.; Rylands, A. B.; Queiroz, H. L.; Pinto, L. P.; Masterson, D. \& Cavalcanti, R. B. 2005. Os corredores ecológicos das florestas tropicais do Brasil. Sociedade Civil Mamirauá, Belém, 256p.

Borém, R. A. T. \& Ramos, D. P. 2001. Estrutura fitossociológica da comunidade arbórea de uma topossequência pouco alterada de uma área de Floresta Atlântica, no município de Silva Jardim-RJ. Revista Árvore 25: 131-140.

Borém, R. A. T. \& Oliveira-Filho, A. T. 2002. Fitossociologia do estrato arbóreo em uma topossequência alterada de Mata Atlântica no município de Silva Jardim-RJ, Brasil. Revista Árvore 26: 727-742.

Brower, J. E. \& Zar, J. H. 1984. Field and laboratory methods for general ecology. W. C. Brown, Iowa, 226p.

Carvalho, F. A.; Nascimento, M. T. \& Braga, J. M. A. 2006. Composição e riqueza florística do componente arbóreo da Floresta Atlântica submontana na região de Imbaú, município de Silva Jardim, RJ. Acta Botanica Brasilica 20: 727-740.

Carvalho, F. A.; Nascimento, M. T. \& Braga, J. M. A. 2007. Estrutura e composição florística do estrato arbóreo de um remanescente de Mata Atlântica submontana no município de Rio Bonito, RJ, Brasil (Mata Rio Vermelho). Revista Árvore 31: 717-730.
Carvalho, F. A.; Nascimento, M. T. \& OliveiraFilho, A. T. 2008. Composição, riqueza e heterogeneidade da flora arbórea da bacia do rio São João (estado do Rio de Janeiro, Brasil). Acta Botanica Brasilica 22: 929-940.

Causton, D. R. 1988. An introduction to vegetation analysis, principles, practice and interpretation. Unwin Hyman, London, 342p.

Dean, W. 1996. A ferro e fogo: a história e a devastação da Mata Atlântica brasileira. Companhia das Letras, São Paulo, 484p.

Fernandes, R. W.; Rambaldi, D. M. \& Teixeira, A. M. G. 2008. Restauração e proteção legal da paisagem - corredores florestais e RPPNs. In: Procópio de Oliveira, P.; Grativol, A. D. \& Ruiz Miranda, C. R. (orgs.). Conservação do micoleão-dourado: enfrentando os desafios de uma paisagem fragmentada. Série Ciências Ambientais v.3. Universidade Estadual do Norte Fluminense, Campos dos Goytacazes. Pp. 160-179.

Fundação SOS Mata Atlântica. 2002. Atlas da evolução dos remanescentes florestais e ecossistemas associados no domínio da Mata Atlântica no período 1995-2000. Fundação SOS Mata Atlântica/INPE, São Paulo. http//www.sosmataatlantica.org.br (acessado em 15/03/2007).

Gandolfi, S.; Leitão-Filho, H. F. \& Bezerra, C. L. F. 1995. Levantamento florístico e caráter sucessional das espécies arbustivo-arbóreas de uma floresta mesófila semidecídua no município de Guarulhos, SP. Revista Brasileira de Biologia 55: 753-767.

Guedes-Bruni, R. R. 1998. Composição, estrutura e similaridade de dossel em seis unidades fisionômicas de Mata Atlântica no Rio de Janeiro. Tese de Doutorado. Universidade de São Paulo, São Paulo, 347p.

Guedes-Bruni, R. R.; Silva-Neto, S. J.; Morim, M.P. \& Mantovani, W. 2006a. Composição florística e estrutura de dossel em trecho de floresta ombrófila densa atlântica sobre morrote mamelonar na Reserva Biológica de Poço das Antas, Rio de Janeiro, Brasil. Rodriguésia 57: 429-442. 
Guedes-Bruni, R. R.; Silva-Neto, S. J.; Morim, M. P. \& Mantovani, W. 2006b. Composição florística e estrutura de trecho de floresta ombrófila densa atlântica aluvial na Reserva Biológica de Poço das Antas, Silva Jardim, Rio de Janeiro, Brasil. Rodriguésia 57: 413-428.

Hart, T. B.; Hart, J. A. \& Murphy, P. G. 1989. Monodominant and species-rich forests of the humid tropics: causes for their cooccurrence. The American Naturalist 133: 613-633.

Hubbel, S. P.; Foster, R. B.; O’Brien, S. T.; Harms, K. E.; Condit, R.; Wechsler, B.; Wright, S. J. \& Lao, S. L. 1999. Light gaps disturbance, recruitment limitations and tree diversity in a Neotropical forest. Science 283: 554-557.

Kierulff, M. C.; Rambaldi, D. M. \& Kleiman, D. G. 2005. Passado, presente e futuro do mico-leão-dourado e de seu hábitat. In: Galindo-Leal, C. \& Câmara, I. G. (eds.). Mata Atlântica: biodiversidade, ameaças e perspectivas. Fundação SOS Mata Atlântica/Conservação Internacional, Belo Horizonte. Pp. 95-102.

Kovach, W. L. 2004. MVSP (Multivariate Statistical Package), version $3.13 \mathrm{~m}$. Kovach Computing Service, Wales.

Kurtz, B. C. \& Araujo, D. S. D. 2000. Composição florística e estrutura do componente arbóreo de um trecho de Mata Atlântica na Estação Ecológica Estadual do Paraíso, Cachoeira de Macacú, Rio de Janeiro, Brasil. Rodriguésia 51: 69-112.

Laurance, W. F. \& Bierregaard, R. O. (eds.). 1997. Tropical forest remnants: ecology, management and conservation of fragmented communities. Chicago University Press, Chicago, 616p.

Lima, J. A. S.; Villela, D. M.; Pérez, D. V.; Calderano Filho, B. \& Nascimento, M. T. 2007. Avaliação da biomassa radicular fina em fragmentos florestais da planície costeira fluminense. Revista Brasileira de Biociências 5: 450-452.

Martins, F. R. 1993. Estrutura de uma floresta mesófila. UNICAMP, Campinas, 246p.
Matsuo, P. M.; Rambaldi, D. M.; Bento, M. I. S.; Fernandes, R. W. \& Boucinha, V. 2008. Educação ambiental e políticas públicas para a conservação do mico-leão-dourado. In: Procópio de Oliveira, P.; Grativol, A. D. \& Ruiz Miranda, C. R. (orgs.). Conservação do mico-leão-dourado: enfrentando os desafios de uma paisagem fragmentada. Série Ciências Ambientais v.3. Universidade Estadual do Norte Fluminense, Campos dos Goytacazes. Pp. 180-195.

MMA. 2000. Avaliação e ações prioritárias para a conservação da biodiversidade da Mata Atlântica e Campos Sulinos. MMA/ SBF, Brasília, 322p.

Moreno, M. R.; Nascimento, M. T. \& Kurtz, B. C. 2003. Estrutura e composição florística do estrato arbóreo em duas zonas altitudinais na Mata Atlântica de encosta da região do Imbé, RJ. Acta Botanica Brasilica 17: 371-386.

Mori, S. A.; Boom, B. M. \& Prance, G. T. 1981. Distribution patterns and conservation of eastern Brazilian coastal forest species. Brittonia 33: 233-245.

Mori, S. A.; Boom, B. M., Carvalho, A. M. \& Santos, T. S. 1983. Ecological importance of Myrtaceae in an Eastern Brazilian Wet Forest. Biotropica 15: 68-70.

Mueller-Dombois, D. \& Ellenberg, H. 1974. Aims and methods of vegetation ecology. John \& Wiley Sons, New York, 347p.

Myers, N.; Mittermeier, R. A.; Mittermeier, C. G.; Fonseca, G. A. B. \& Kent, J. 2000. Biodiversity hotsposts for conservation priorities. Nature 403: 845-853.

Neves, G. M. S. 1999. Florística e estrutura da comunidade arbustivo-arbórea em dois remanescentes de floresta atlântica secundária - Reserva Biológica de Poço das Antas, Silva Jardim, RJ. Dissertação de Mestrado. Universidade Federal do Rio de Janeiro, Rio de Janeiro, 115p.

Parrota, J. A. 1993. Secondary forest regeneration on degraded tropical lands: the role of plantations as "faster ecosystems". In: Lieth, H. \& Lohmann, M. (eds.). Restoration of 
tropical forest ecosystems. Kluwer Academic Publishers, Netherlands. Pp. 63-73.

Peixoto, G. L. \& Costa-Júnior, W. J. 2004. A rodovia BR-101 e seus impactos na Reserva Biológica União, Rio de Janeiro, Brasil. In: Anais do IV Congresso Brasileiro de Unidades de Conservação, vol. 2. Fundação O Boticário de Proteção à Natureza: Rede Nacional Pró Unidades de Conservação, Curitiba. Pp. 307-315.

Pessoa, S. V. A. 2003. Aspectos da fragmentação em remanescentes florestais da planície costeira do estado do Rio de Janeiro. Dissertação de Mestrado. Universidade Federal Rural do Rio de Janeiro, Rio de Janeiro, 112p.

Pessoa, S. V. A. \& Oliveira, R. R. 2006. Análise estrutural da vegetação arbórea em três fragmentos florestais na Reserva Biológica de Poço das Antas, Rio de Janeiro. Rodriguésia 57: 391-412.

Primo, P. B. \& Volker, C. M. 2003. Bacias hidrográficas dos rios São João e das Ostras - águas, terras e conservação ambiental. Consórcio Intermunicipal Lagos São João, Rio de Janeiro, 115p.

Procópio de Oliveira, P.; Nascimento, M. T.; Carvalho, F. A.; Villela, D.; Kierulff, M. C. M.; Veruli, V. P.; Lapenta, M. J. \& Silva, A. P. 2008. Qualidade do habitat na área de ocorrência do mico-leão-dourado. In: Procópio de Oliveira, P.; Grativol, A. D. \& Ruiz Miranda, C. R. (orgs.). Conservação do mico-leão-dourado: enfrentando os desafios de uma paisagem fragmentada. Série Ciências Ambientais v.3. Universidade Estadual do Norte Fluminense, Campos dos Goytacazes. Pp. 14-39.

Rambaldi, D. M. \& Oliveira, D. A. S. (orgs.). 2005. Fragmentação de ecossistemas: causas, efeitos sobre a biodiversidade e recomendações de políticas públicas, $2^{\mathrm{a}} \mathrm{ed}$. MMA/SBF, Brasília, 508p.

Rodrigues, P. J. F. P. 2004. A vegetação da Reserva Biológica União e os efeitos de borda na mata atlântica fragmentada. Tese de Doutorado. Universidade Estadual do Norte Fluminense, Campos dos Goytacazes, 153p.

Tabarelli, M.; Pinto, L. P.; Silva, J. M. C.; Hirota, M. M. \& Bedê, L. C. 2005. Desafios e oportunidades para a conservação da biodiversidade na Mata Atlântica brasileira. Megadiversidade 1: 132-138.

Terborgh, J. 1992. Maintenance of diversity in tropical forests. Biotropica 24: 283-292.

Thomaz, W.M. W.; Carvalho, A. M. V.; Amorim, A. M. A.; Garrison, J. \& Arbeláez, A. L. 1998. Plant endemism in two forests in southern Bahia, Brazil. Biodiversity and Conservation 7: 311-322.

Tilman, D.; May, R. M.; Lehman, C. L. \& Nowak, M. A. 1994. Habitat destruction and the extinction debt. Nature 371: 65-66.

Turner, I. M.; Chua, K. S.; Ong, J.; Soong, B. \& Tan, H. 1996. A century of plant species loss from an isolated fragment of lowland tropical rainforest. Conservation Biology 10: 1229-1244.

Veloso, H. P.; Rangel Filho, A. L. R. \& Lima, J. C. A. 1991. Classificação da Vegetação Brasileira, adaptada a um sistema universal. IBGE, Rio de Janeiro, 123p.

Viana, V. M.; Tabanez, A. A. J. \& Batista, J. 1997. Dynamics and restoration of forest fragments in the Brazilian Atlantic moist forest. In: Laurance, W. F. \& Bierregaard, R. O. (eds.). Tropical forest remnants: Ecology, management and conservation of fragmented communities. University of Chicago Press, Chicago. Pp. 351-365. 